may favour a sectorised service, physicians find the allocation of patients by address irksome and incomprehensible. Very few liaison services have specialised in-patient facilities, so if the patient has to be admitted to a psychiatric unit, the psychiatrist loses the satisfaction of continuity of patient care. A common aggravation of liaison work is the lack of privacy when interviewing patients on medical wards. There are usually no interview rooms, and this means that some interviews are conducted in side rooms, broom cupboards or even toilets! It is essential for the new liaison psychiatrist to be assertive and see cases only if there has been adequate preparation of the patient by the physician and there is a quiet, private, facility in which to interview the patient. Without such a stand the psychiatrist's opinion may be disregarded. Another problem can be the initial wariness of nursing staff towards the psychiatrist, although it can be particularly gratifying to witness this change as the psychiatrist comes to be perceived as a valuable resource.

\section{Research}

Research in this relatively new field of psychiatry is burgeoning. It covers a wide spectrum including both biological and social aspects of psychiatry. There are numerous opportunities for collaborative projects with medical and surgical colleagues (many of whom are anxious for such a collaborator but have not found a suitable psychiatrist), to establish the role of psychological factors both in the aetiology and management of physical illness. Useful projects can still be done without sophisticated resources and prevalence surveys are still of value, if sensible comparison groups are chosen. In addition, there is increasing research interest in somatisation patients who present to the physician or surgeon with nonorganic physical symptoms. Audit of liaison psy- chiatry services is clearly necessary, and some American work has already demonstrated that psychiatric intervention with certain group of patients reduces the overall cost of treatment and leads to improved patient care.

\section{Conclusion}

Most general consultant posts involve a degree of liaison psychiatry, and it is possible for any interested psychiatrist to develop this further. Unfortunately, too many consultants have not been exposed to proper liaison psychiatry as senior registrars and do not know how to go about developing a liaison service. It is well worth gaining first-hand experience in a specialised centre, as a senior registrar. Patchy development of more specifically liaison posts will continue, but such posts may be sparse and consequently difficult to obtain. Liaison psychiatry is a stimulating career choice, and may particularly suit a confident, clinically-orientated, psychiatrist who is able to communicate clearly and simply, and forge effective links with medical colleagues.

\section{Further reading}

ANDERSON, H. M. (1989) Liaison psychiatry in Scotland: the present service. Psychiatric Bulletin, 13, 606-608.

MAYOU, R. \& LLOYD, G. (1985) A survey of liaison psychiatry in the United Kingdom and Eire. Bulletin of the Royal College of Psychiatrists, 9, 214-217.

- Anderson, H., Feinmann, C., Hodgson, G. \& Jenkins, P. L. (1990) The present state of consultation and liaison psychiatry. Psychiatric Bulletin, 14, 321-325.

Sensky, T., Greer, S., Cundy, T. \& Pettingale, K. (1985) Referrals to psychiatrists in a general hospital comparison of two methods of liaison psychiatry: preliminary communication. Journal of the Royal Society of Medicine, 78, 463-468.

\title{
Career information pack and poster
}

The Public Education Committee has recently produced a career information pack and two posters which are available for Careers Fairs free of charge, and are aimed particularly at medical students thinking of specialising in psychiatry.
The committee also hopes to produce a short video which should be available later on in the year, on 'The day in the life of a psychiatrist'.

Copies of the posters and the careers packs are available from Deborah Hart at the College upon request. 